principal primero porque las micro-finanzas no se limitan a los servicios de crédito sino también a los de ahorro, seguros y transferencias de dinero, y segundo, porque en mercados financieros como el chileno, la disponibilidad de crédito no es una barrera fundamental atendida la vasta oferta de crédito de consumo en sus variadas (y por cierto también onerosas) formas.

Si la educación pasa por enseñar, por ejemplo en los niveles de instrucción técnico-profesional, las herramientas básicas de matematicas financieras, también el foco general deberia apune postergar consumo discrecional, por minimo que sea.

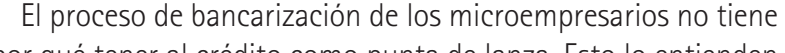
por qué tener al creatito como punta de lanza. Esto lo entienden donde el fis encrento basat surge de los recursos aportados primero por la familia luego por los amigos y en seguid oor los creyentes (family friends and fools se suele decir) mucho antes que el mero endeudamiento. Lo entienden también muchos bancos que comienzan ofreciendo chequeras electrónicas y cuentas de ahorro antes que préstamos.

En el caso chileno como en otros donde operan prestamistas organizados como entidades sin fines de lucro, estas cumplen un papel de educación importante. La cercania con los microde modo natural y la sola exigencia de un simple plan de negocios tiene valor pedagógico. Sin embargo, ya sabemos que educación implicita se paga con tasas de interés altas. En el caso de Banigualdad y Esperanza, dos de las instituciones formales del rubro, las tasas (en torno al 2 por ciento mensuall) son similares a las de un credito de consumo. Además, al tratarse como alternativa al endeudamiento tiende a ocupar un lugar secundario.

Si no se quiere incentivar la captación de ahorros en instituciones no reguladas por la SBIF, por el riesgo sistémico que ello pudier acarrear, la alternativa de educar en el ahorro dentro de los establecimientos de instrucción escolar formal cobra mayor sentido. En el ámbito bancario, BanEstado tiene una tradición de administración de pequeñas cuentas de ahorro y una base de el microcrédito. En 2006 rentó 54 por ciento sobre el capita asignado a nogcio 2006 rento 54 por ciento sobre el capita vender su experiencia en la forma de servicios de instrucción vender su experiencia en la forma de servicios de instrucción ciones que sustentan a los intermediarios de microcrédito pero, sesgado hacia el endeudamiento.

${ }^{2}$ Mix Market, Microbulletin 2011

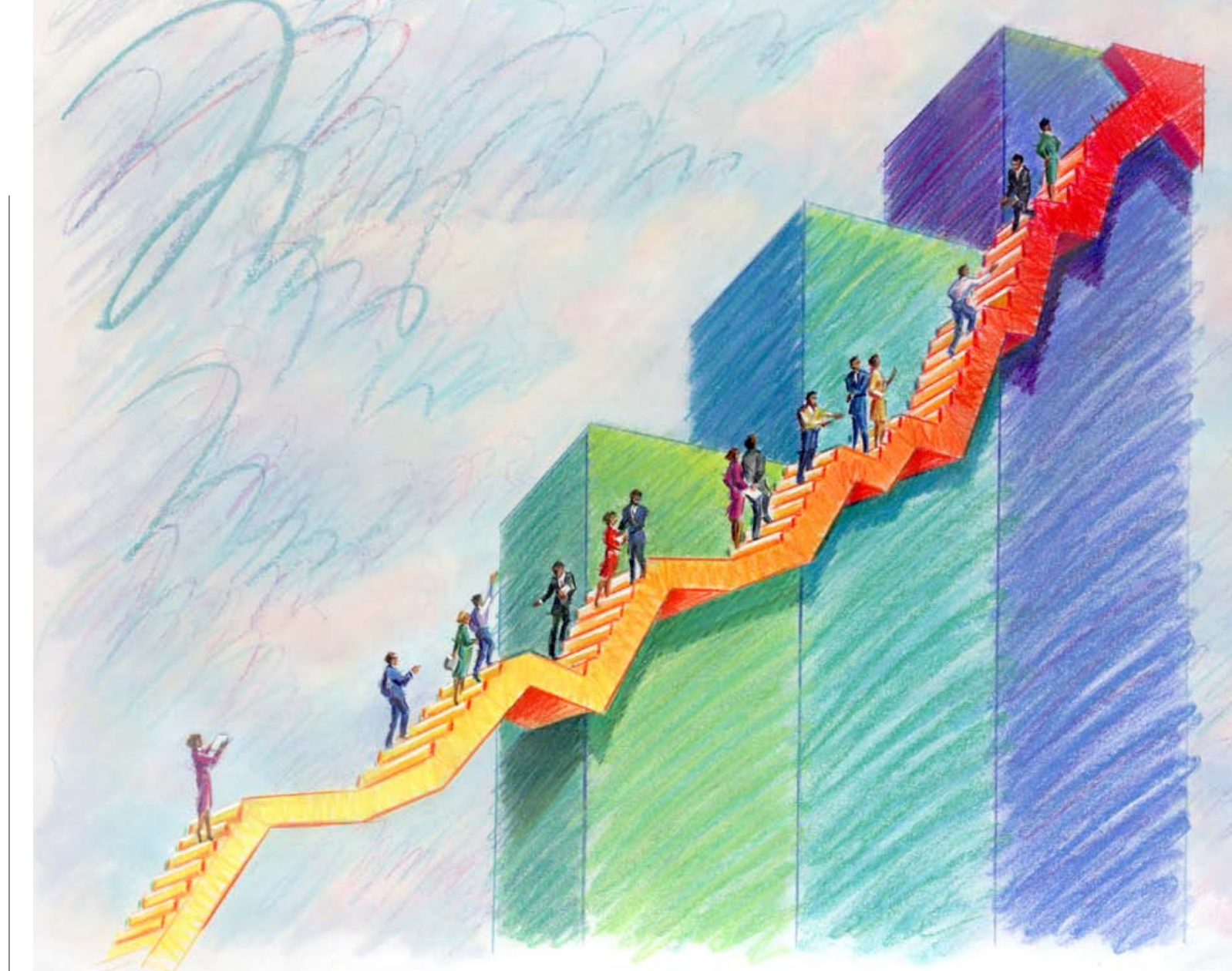

\section{¿Empleo pleno?}

Por Marcela Perticará ${ }^{*}$ *Ph.D. en Economía, University of Texas A\&tM, EE.UU. Profesora
Facultad de Economia y Negocios, UAH.

Desde principios de año, tanto desde el gobierno como desde la de empleo. Dos encuestas de reencia (la de la U. de Chile y la de INE) mostraban importantes caidas en las tasas de desempleo: 2 3 puntos porcentuales en aproximadamente 24 meses. Todo esto acompañado de un crecimiento sostenido en la tasa de participación de las mujeres.

La Nueva Encuesta Nacional de Empleo del INE (NENE) sufrió modifcaciones importantes tanto en el marco muestral como en rales chilenas a las vigentes en paises de la OECD. En particular cambió la pregunta para indagar la situación de empleo. En la ENE se preguntaba por la situación laboral del encuestado en la semana anterior a la encuesta. En la NENE se pregunta a los individuos si trabajaron al menos una hora en la semana anterior, y por consiguiente se clasifica como ocupados a quienes señalan que si. La nueva manera de preguntar efectivamente puede estar "inflando" el número de personas ocupadas. asalariado, con un leve repunte del aquel por cuenta propia ${ }^{2}$. Más aun: la estabilidad
del crecimiento (5\% a 12 meses) parece tener en cuenta qué ha pasado con los ni-

travisitroversia- la tendencia en la tasa de eminstrumento de medición. Incluso si utilzáramos las cifras referenciales de la NENE para el año 2009', ellas mostrarian (aún con un desfase en niveles) que la tendenci a la baja en la tasa de desempleo era evidente en los últimos meses de 2009. Un hecho importante a destacar es que la ba de la tasa de desempleo a fines de ese año estaba siendo ayudada por una caida participacion, mientras que en la actualidad tenemos desempleo cayendo y particpación subiendo. La encuesta de empleo de la Universidad de Chile para el Gran Santia$\checkmark$ arroja conclusiones similares.

"Es harina de otro costal qué tan buen "espejo de la creación de trabajos es que refleja la NENE (io incluso el que reflejaba antigua encuestal!) Por suerte, la nuva encuesta permite evaluar, al menos en términos netos, algunas caracteristicas de los empleos creados. Durante el año 2010 los grupos ocupacionales con mayores tasas de crecimiento entre hombres y mueres son los empleos independientes, patrones y cuenta propia, un tipo de empleo sectores con menores tasas de cesantía que no siempre es de alta productividad. Pero, durante 2011, la incidencia de estas del empleo está sustentada por empleo del crecimiento (5\% a 12 meses) parece no depender del factor estacional. Entre los hombres, la mayorla del empleo creado (en terminos netos) es a tiempo completo; aproximadamente un 50\% de los empeos creados fueron de menos de 30 horas a semana. Con todo, la fracción de mujeres que declara tener jornada parcial pero querer jornada completa se ha mantenido casi invariable en torno al 50\% en los últimos 24 meses. No es evidente que el mercado aboral chileno esté creando empleos particularmente de mala "calidad".

Para analizar si efectivamente estamos o no en situación de pleno empleo, hay que sectores de a y cesantia en los distintos ocupacion el comportamiento y niveles actuales de la oferta laboral.

do tomamos en consideración los niveles n las tasas de participación de hombres 730) y mujeres (48\%). Sumando a estos numeros a las personas que declaran no estar trabajando por motivos permanentes sas ascienden a 840 pension, estas tases ascienden a $84 \%$ y $62,5 \%$. Cierto que a 政 sieran trabajar bajo condiciones de salarios jornada adecuadas.

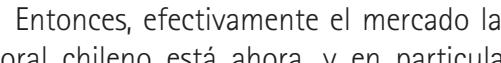
en algunos sectores, mucho más apretado hoy que hace un par de años. Pero hay aún margen de maniobra: incorporar a inactivos al mercado laboral, generar mejores condiciones de trabajo en algunos sectores conómicos de tal manera de producir reconversión de mano de obra y seguramente también seráa necesario invertir fuertecon fondos achación (no necesariamente politica grantes calificados $y$ no calficad Inmillegado al pais y en tasas crecientes los últimos 10 años Si las condiciones del mercado laboral se mantienen, van a seguir haciéndolo, sin que sea necesario, ni conveniente, a mi juicio, algún tipo de intertores económicos, con sectores como construcción y servicios inmobiliarios que presentan tasas de cesantía un 40\% más altas que el promedio, mientras que otros les, agricultura, instituciones financieras $y$ pesca y mineria, registran tasas de cesantia cercanas al 4\% (el promedio es 5.4\%). En el trimestre diciembre-febrero 2012 los fueron aquellos que mostraron alto di(c) administración pública instituciones financieras) y la agricultura cuyas tasas de cesantía en sus períodos estacionales peak se han mantenido extremadamente bajas en las últimas dos mediciones. Solo con estas cifras en mente, uno diría que hay sectores en claro pleno empleo (al menos tros como minería, pesca y servicios, en los que el margen se está r duciendo de manera muy rápida. Ahora bien, al mismo tiempo, el pleno empleo en Chile parece una panacea cuan- 